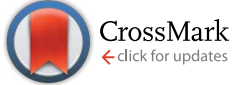

Cite this: RSC Adv., 2017, 7, 6712

Received 26th October 2016 Accepted 5th December 2016

DOI: $10.1039 / c 6 r a 25860 c$

www.rsc.org/advances

\section{Iron oxide nanoparticles functionalized with nisin for rapid inhibition and separation of Alicyclobacillus spp.}

\begin{abstract}
Zihan Song, Yahong Yuan, Chen Niu, Lu Dai, Jianping Wei and Tianli Yue*
Alicyclobacillus acidoterrestris can spoil various fruit juices, and tools to reduce the impact of this contaminant are urgently needed. Here, we describe a novel therapeutic approach in which iron oxide nanoparticles (IONPs) were conjugated with the known antibiotic nisin (IONPs-nisin). The size, crystalline nature, magnetic characteristics and surface charge of the nanoparticles were characterized with transmission electron microscopy (TEM), X-ray diffraction (XRD), vibrating sample magnetometry (VSM) and Zetasizer Nano ZS (Zeta). The average diameter of the IONPs was $30 \pm 7 \mathrm{~nm}$. The TEM and XRD data indicated that the IONPs were very spherical magnetic particles with a single crystalline phase. The VSM study showed that the IONPs were superparamagnetic with a saturation magnetization (MS) of about 33 emu $\mathrm{g}^{-1}$. The IONPs had a negative charge of around $-32.8 \mathrm{mV}$ at $\mathrm{pH}$ 7.0. The optimal preparation of IONPs-nisin composites was at $\mathrm{pH} 7.0$ with a $2: 1$ (IONPs : nisin) ratio for $1 \mathrm{~h}$. FT-IR data confirmed conjugation of IONPs to nisin, and the composites retained $86.69 \%$ of their antimicrobial activity after storage for 7 days at $4{ }^{\circ} \mathrm{C}$ and $83.46 \%$ after storage for 7 days at $25{ }^{\circ} \mathrm{C}$. The products retained their antibacterial activity after treatment at $\mathrm{pH} 2$ to 11 . The minimum inhibitory concentration (MIC) of IONPs-nisin composites against A. acidoterrestris DSM 3923 was $2.5 \mathrm{mg} \mathrm{mL}^{-1}$ of AAM medium $(\mathrm{pH}$ 4.2). Finally, we used the CFDA-SE leakage assay and scanning electron microscopy (SEM) to show that the IONPs-nisin inhibited target strains via pore formation in the membrane-this is the same as with nisin. These composites retained the features of both nisin and IONPs. The composites were easily separated from the sample via a magnet after being deployed as antimicrobials. To the best of our knowledge, this is the first report of an IONP-nisin composite with significant implications to the food safety community. These products might be useful tools for controlling spoilage due to $A$. acidoterrestris.
\end{abstract}

\section{Introduction}

Alicyclobacillus is a global challenge to food quality and can survive typical heat processing. It is the main cause of spoilage in a variety of fruit juices. Spoilage incidents due to Alicyclobacillus acidoterrestris have been found in apple juice, ${ }^{\mathbf{1}}$ mango juice, ${ }^{2}$ pear juice $^{3}$ and other acidic beverages. ${ }^{4}$ Strains are common in soil from the Orchard ${ }^{5-8}$ and contaminate the juice through a variety of unknown access routes. Most Alicyclobacillus species are both heat-resistant and acid-tolerant. They can grow from $20-75{ }^{\circ} \mathrm{C}$ with a $\mathrm{pH}$ range of 2 to $6 .{ }^{9}$ There are broad economic losses due to Alicyclobacillus, ${ }^{\mathbf{1 0}}$ and new tools to control Alicyclobacillus spoilage are urgently needed.

Established antibacterial substances including natural and synthetic compounds as well as innovative methods including irradiation with electron, gamma beams, microwaves, high hydrostatic pressure and high pressure homogenization can inhibit Alicyclobacillus. ${ }^{\mathbf{1 1}, 12}$ One such novel approach is the

College of Food Science \& Engineering, Northwest A\&F University, 712100 Yangling, Shaanxi, China. E-mail: yuetl305@nwsuaf.edu.cn; Tel: +86-29-87092492 bacteriocins-natural antimicrobial agents with no off-target toxicity. One of the most common bacteriocin is nisin, which has been extensively studied and approved as a food additive. ${ }^{\mathbf{1 3 - 1 5}}$

To control Alicyclobacillus acidoterrestris, nisin has been used alone $^{16,17}$ or in a variety of novel products: nisin-incorporated films, ${ }^{18}$ nisin synergistically interacting with Piperaceae extracts ${ }^{19}$ nisin combined with sodium benzoate or potassium sorbate, ${ }^{20}$ nisin combined with thermal treatments, ${ }^{15}$ and nisin combined with high pressure. ${ }^{21}$ Nevertheless, one study found that nisin can inhibit many human intestinal bacteria. ${ }^{22}$ To solve this, some recent reports have described nanomaterial conjugates of nisin that can inhibit resistant bacteria and then be easily separated from the food product. ${ }^{23,24}$

Magnetic iron oxides are easily synthesized compounds with unique characteristics and widespread applications. ${ }^{25}$ Magnetic IONPs are low cost, superparamagnetic, low toxicity, environmentally safe, easily magnetically separate, and biocompatibility. ${ }^{25,26}$ However, to the best of our knowledge, there is no report of IONPs being functionalized with nisin. Here, for the first time, we report the integration of magnetic iron oxide nanoparticles with nisin via electrostatic adsorption. The 
complex not only conserves the effective inhibition of nisin towards Alicyclobacillus, but the magnetic nature of the nanoparticle facilitates easy separation. This product has strong activity against Alicyclobacillus and is temporally stable across a variety of $\mathrm{pH}$ challenges.

\section{Results and discussion}

\section{Optimization of IONPs-nisin composites preparation conditions}

Fig. 1 shows that interaction between IONPs and nisin was based on physical absorption-anionic IONPs were absorbed by the cationic nisin. The most important parameters were $\mathrm{pH}$, reaction time, and proportion of IONPs to nisin.

The $\mathrm{pH}$ value was studied from 2.0-10.0, and the maximum inhibition occurred at $\mathrm{pH} 7.0$ and 8.0 (Fig. 2a). The $\mathrm{pH}$ variation has an appreciable influence on the interaction between IONPs and nisin, which results from the rationale of the preparation of IONPs-nisin composites. Apparently, the inhibition activity has no significant difference between $\mathrm{pH} 7.0$ and 8.0 taking the error range into account. Therefore, the optimal $\mathrm{pH}$ was selected as 7.0.

The optimal proportion of the IONPs and nisin in the process of the preparation of IONPs-nisin was investigated (Fig. 2b). As the proportion of nisin and IONPs increased from $1: 0.5$ to $1: 2$, the inhibitory zone diameters grew sharply. Although the proportion continuously increased to $1: 4$, there was no significant change. Therefore, $1: 2$ (nisin/IONPs) was selected.

The reaction time was varied from $0.5 \mathrm{~h}$ to $4 \mathrm{~h}$. The goal was a short reaction time with good performance. Fig. $2 \mathrm{c}$ shows that one hour was sufficient and offered satisfactory results. Therefore, $1 \mathrm{~h}$ was used for all subsequent studies.

Fig. 2d shows that the zone of inhibition of both IONPsnisin composites and homologous supernatant vanished after the sixth formation of IONPs-nisin. Hence, the maximum adsorption proportion was $12: 1$ (IONPs : nisin).

\section{Characterization of IONPs with/without nisin}

TEM (Fig. 3a) shows the morphology and particle size of the IONPs with an average diameter of $30 \pm 7 \mathrm{~nm}$. The lattice planes corresponding to IONPs were analyzed by electron diffraction (Fig. 3b). Different ring diameters are shown in Fig. 3b indicating the different lattice planes of the IONPs. The fringe patterns demonstrated that the IONPs are single crystalline. Fig. 3c shows two adjacent planes on the IONPs surface. These were marked in the image and indicated a lattice separation of $0.296 \mathrm{~nm}$ and $0.253 \mathrm{~nm}$, which corresponded to the (220) and (311) lattice planes (JCPDS card no. 19-0629). Fig. 3b and c show that the IONPs were mixed with no impurities.

XRD patterns of the IONPs are shown in Fig. 4. The diffractogram of the IONPs had peaks at $2 \theta$ of $30^{\circ}, 35.6^{\circ}, 43.3^{\circ}, 57^{\circ}$ and $62.7^{\circ}$ corresponding to signals from the (220), (311), (400), (511) and (440) crystalline planes, respectively (JCPDS card no. 19-0629). According to the Debye-Scherrer equation, the average crystallite size of the IONPs calculated from the FWHM of the XRD peaks was $\sim 30.29 \mathrm{~nm}$, which agreed nicely with the TEM data.

Hysteresis loops of the IONPs were carried out at room temperature using vibrating sample magnetometry (VSM) to characterize the magnetic properties. Fig. 5 shows that the

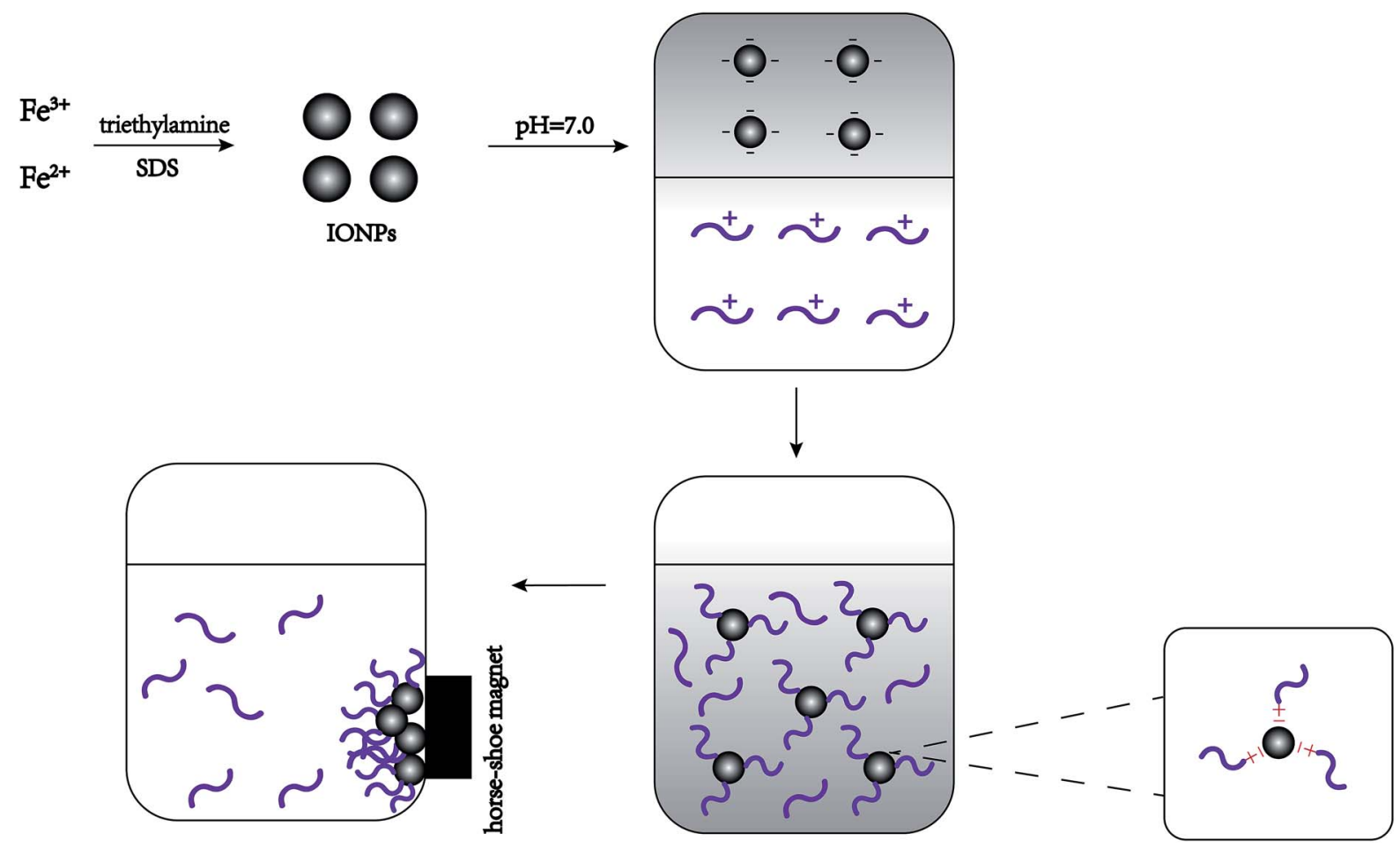

Fig. 1 Schematic representation showing the synthetic procedure for the formation of nisin antimicrobials peptide attached IONPs. 

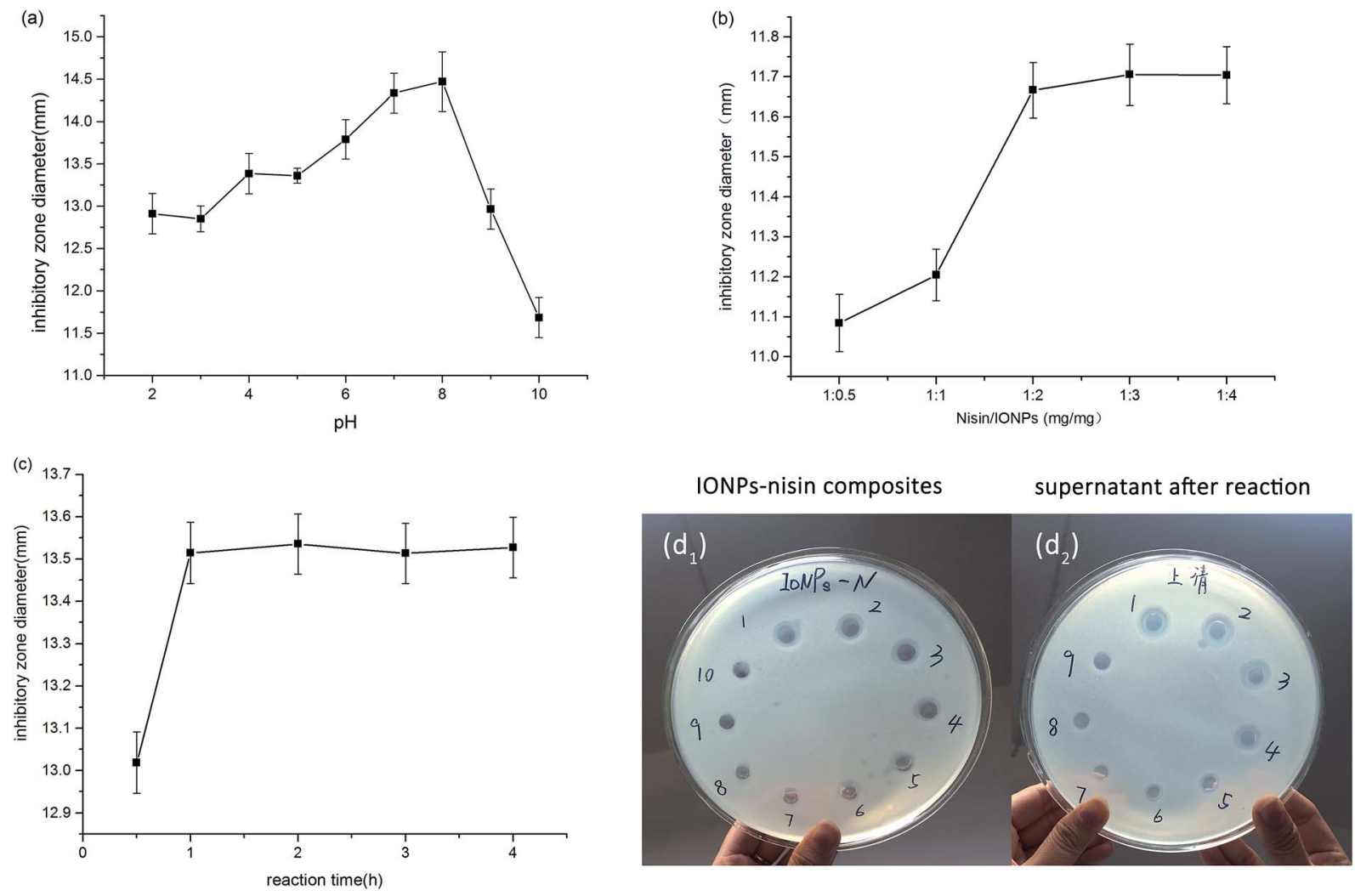

Fig. 2 Effect of (a) pH of the system, (b) the proportion of nisin and IONPs, (c) the reaction time on the preparation of IONPs-nisin composites. (d) Agar well diffusion assay to ascertain the maximum adsorption concentration of IONPs/nisin. $10 \mathrm{mg} \mathrm{ONPs}$ were added to nisin (1 mg $\mathrm{mL}^{-1}$ ) to obtain IONPs-nisin composite followed by magnetic separation. This process was repeated 10 times, and $100 \mu \mathrm{L}$ of the supernatant was reserved after each reaction. 1-10 $\left(d_{1}\right)$ and 1-10 $\left(d_{2}\right)$ represented the number of addition times.

saturation magnetization $\left(M_{\mathrm{S}}\right)$ was about $33 \mathrm{emu}^{-1}$, and the Sshaped magnetic hysteresis loops of the IONPs exhibited zero remanence and coercivity, which indicated that the nanoparticles are superparamagnetic.

The zeta potential was carried out at $\mathrm{pH} 7.0$ because the IONPs interact with nisin best at neutral $\mathrm{pH}$. The IONPs had a negative charge of around $-32.8 \mathrm{mV}$ at $\mathrm{pH} 7.0$ (Fig. 6) due to the charge-based synthesis of IONPs-nisin composites.

FT-IR was used to demonstrate the presence of nisin on the surface of the IONPs (Fig. 7). The spectrum of IONPs-nisin composites has a broad band at $\sim 3415 \mathrm{~cm}^{-1}$ probably due to overlap of two different bands from the free amino groups of nisin and $\mathrm{O}-\mathrm{H}$ stretching vibration of $\mathrm{H}_{2} \mathrm{O}$ adsorbed on the surface of the $\mathrm{Fe}_{3} \mathrm{O}_{4}$ nanoparticles. The broad absorption bands at $\sim 1643 \mathrm{~cm}^{-1}$ are due to the characteristic amide stretching vibrations. These were retained on IONPs-nisin the composites.

\section{Antimicrobial activity of IONPs-nisin composites as a function of $\mathbf{p H}$ and thermal stability}

Table 1 shows that the IONPs-nisin composites retained antibacterial activity after treatment at $\mathrm{pH} 2-11$. The activity was reduced as the composite was treated at lower or higher $\mathrm{pH}$. Specifically, there was no difference in inhibitory activity after treatment at $\mathrm{pH} 4.0-8.0(p>0.05)$, which retained the best ability to inhibit $A$. acidoterrestris. In addition, the inhibitory activity showed no difference when treated at extreme $\mathrm{pH}$ values of 3.0, 9.0, 10.0, and 11.0. However, significant differences were observed after treatment at $\mathrm{pH} 2.0(p<0.05)$. This was due to the dissociation of IONPs-nisin composites at lower $\mathrm{pH}$.

Table 1 also shows that IONPs-nisin composites were heatstable. There was no significant difference in inhibitory activity after heat treatment even up to $60 \min (p>0.05)$. These features are critical for practical applications of this technology. A. acidoterrestris is common in areas without good access to cold storage, and these stabilizing features of the IONP make this approach even more significant.

\section{Storage study}

Fig. 8 illustrates the antimicrobial activity of IONPs-nisin composites after storage at $4{ }^{\circ} \mathrm{C}$ and room temperature $\left(25^{\circ} \mathrm{C}\right)$. The remaining antimicrobial activity was about $86.69 \%$ after storage for 7 days at $4{ }^{\circ} \mathrm{C}$ and $83.46 \%$ after storage for 7 days at $25{ }^{\circ} \mathrm{C}$. As a result, the IONPs-nisin composites can be conveniently stored even at room temperature.

\section{Minimum inhibitory concentration (MIC)}

The MIC of IONPs-nisin composites against $A$. acidoterrestris DSM 3923 was $2.5 \mathrm{mg} \mathrm{mL}^{-1}$ of AAM medium (pH 4.2). The result was approximately the same as the MIC value of nisin reported in the literature. ${ }^{17}$ 

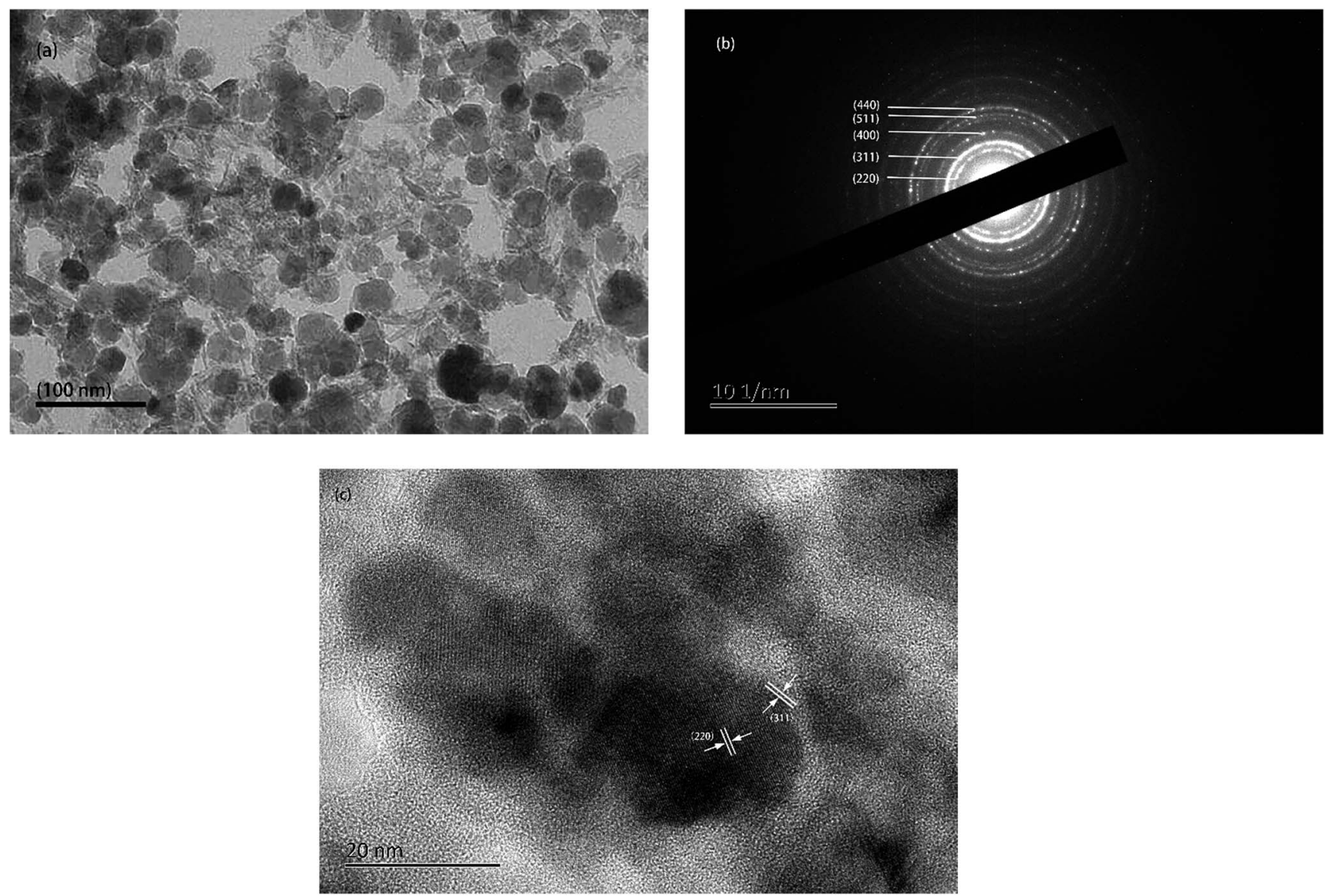

Fig. 3 (a) TEM images, (b) selected area electron diffraction (SAED) pattern, (c) single crystallite lattice fringe pattern.

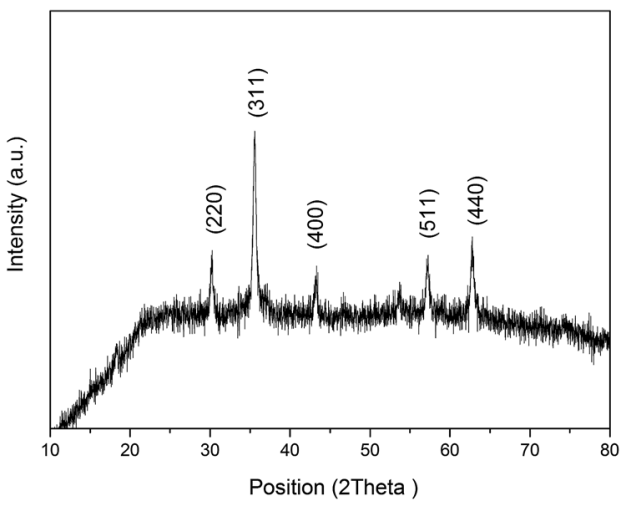

Fig. 4 XRD patterns of IONPs.

\section{CFDA-SE leakage assay}

A CFDA-SE leakage assay was carried out to demonstrate the effect of permeabilising the cytomembrane via IONP-nisin composites.

Fig. 9 shows leakage of CFDA dye after treating with both IONP-nisin composites and nisin. The data indicated membrane destruction. More dye is present with increased reaction time and more antibacterial substances. This trend was due to nisin as indicated by the controls. The IONP-nisin

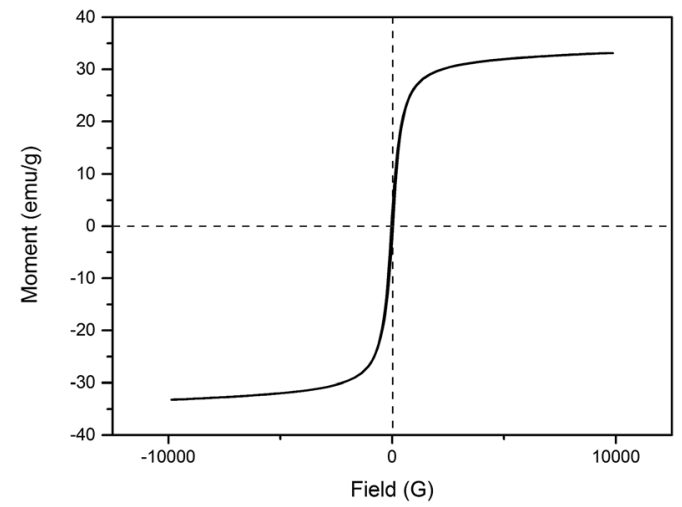

Fig. 5 Hysteresis loops of the IONPs at room temperature.

destroyed the bacterial membrane and caused leakage of the cytoplasmic concentrates to ultimately kill the strain.

\section{Scanning electron microscope (SEM)}

A SEM study was done to identify changes in the DSM 3923 after treatment with IONPs-nisin. The untreated DSM 3923 cells were smooth on the surface and had a normal cellular structure. These retained their integrated cell wall with no debris in the surrounding environment (Fig. 10a). After incubation with the 


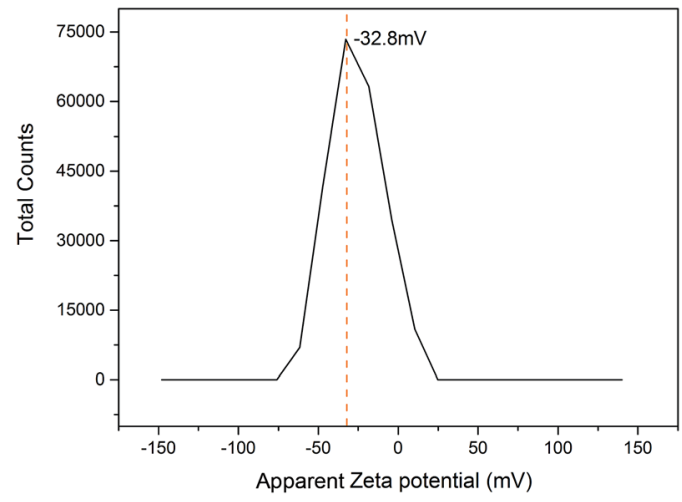

Fig. 6 Zeta potential of IONPs at $\mathrm{pH}$ 7.0.

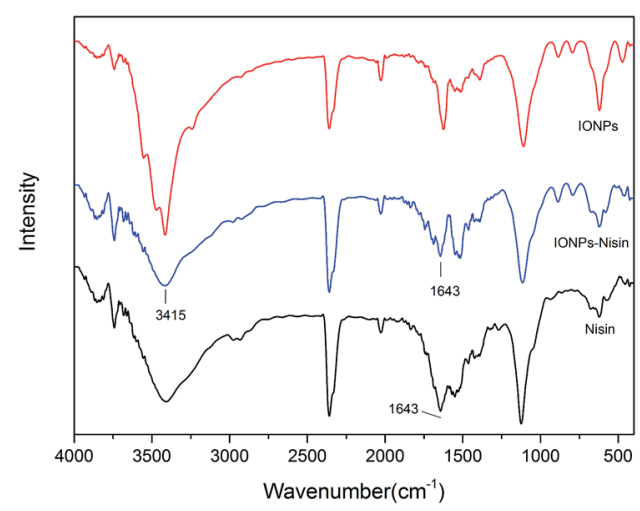

Fig. 7 The comparative FT-IR spectra for IONPs, IONPs-nisin composites and nisin.

Table 1 Effect of $\mathrm{pH}$ and temperature on the stability of IONPs-nisin composites $^{a}$

\begin{tabular}{lc}
\hline Treatment & Residual antimicrobial activity $(\mathrm{mm})$ \\
\hline pH & \\
PBS & $0.00 \pm 0.00$ \\
IONPs & $0.00 \pm 0.00$ \\
7 & $16.83 \pm 0.15^{\mathrm{a}}$ \\
6 & $16.73 \pm 0.15^{\mathrm{a}}$ \\
5 & $16.60 \pm 0.55^{\mathrm{a}}$ \\
4 & $16.59 \pm 0.08^{\mathrm{a}}$ \\
8 & $16.39 \pm 0.28^{\mathrm{a}}$ \\
9 & $15.62 \pm 0.14^{\mathrm{b}}$ \\
3 & $15.44 \pm 0.07^{\mathrm{b}}$ \\
11 & $15.37 \pm 0.12^{\mathrm{b}}$ \\
10 & $15.30 \pm 0.35^{\mathrm{b}}$ \\
2 & $14.6 \pm 0.19^{\mathrm{c}}$ \\
& \\
Temperature & \\
PBS & \\
IONPs & \\
$40{ }^{\circ} \mathrm{C}$ & $0.00 \pm 0.00$ \\
$60{ }^{\circ} \mathrm{C}$ & $0.00 \pm 0.00$ \\
$80{ }^{\circ} \mathrm{C}$ & $14.75 \pm 0.13^{\mathrm{a}}$ \\
$100{ }^{\circ} \mathrm{C}$ & $14.65 \pm 0.12^{\mathrm{a}}$ \\
& $14.57 \pm 0.31^{\mathrm{a}}$ \\
& $14.57 \pm 0.34^{\mathrm{a}}$
\end{tabular}

${ }^{a \text { abc }}$ Significant differences exist between one condition to another when comparing residual antimicrobial activity by Duncan's multiple range test $(p<0.05)$.

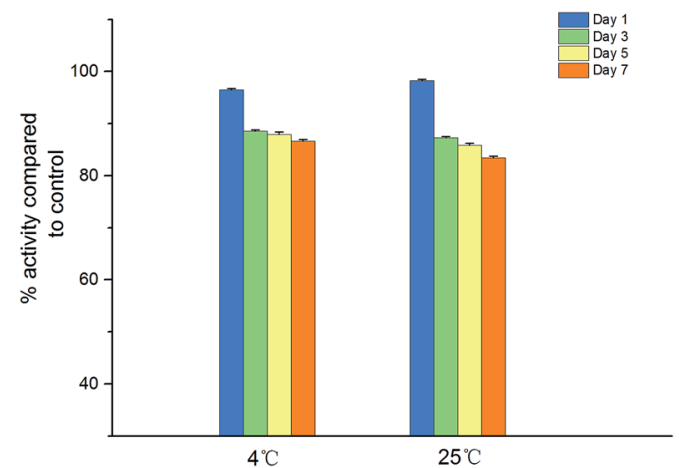

Fig. 8 Effect of the storage time at $4{ }^{\circ} \mathrm{C}$ and $25^{\circ} \mathrm{C}$ on the antimicrobial activity.

IONPs-nisin for $1 \mathrm{~h}$, an irregular and rough cell surface emerged. The cell wall was damaged with pores on the end and in the middle (Fig. 10b and c). There was extensive destruction of the cell morphology when DSM 3923 cells were treated with IONPs-nisin for $2 \mathrm{~h}$ (Fig. 10d). The treatment caused the membrane surface to collapse with disorganization of the bacterial cell leading to cell death.

Extensive studies have shown that the bactericidal mechanism of nisin is pore formation on the cell membrane of the target bacteria. ${ }^{24}$ The SEM and CFDA-SE data show that the IONPs-nisin also disrupts the bacteria membrane similar to free nisin.

\section{Experimental}

\section{Materials}

Nisin and sodium dodecyl sulphate (SDS) were purchased from Sigma-Aldrich (USA). CFDA-SE Cell Proliferation Assay and Tracking Kit (CFDA-SE) was purchased from Enogene, China. Other common reagents were obtained from a local supplier including ferrous sulfate $\left(\mathrm{FeSO}_{4} \cdot 6 \mathrm{H}_{2} \mathrm{O}, 99 \%\right)$, ferric nitrate $\left[\mathrm{Fe}\left(\mathrm{NO}_{3}\right)_{3}, 99 \%\right]$, triethylamine (99.5\%), methanol (99\%), sodium hydroxide ( $\mathrm{NaOH}, 96 \%)$, hydrochloric acid ( $\mathrm{HCl}, 37 \%)$ and phosphate buffer saline (PBS, $\mathrm{pH}$ 7.0).

\section{Bacterial strains and antimicrobial activity assay}

The bacterial strain was $A$. acidoterrestris DSM 3923, which was purchased from the German Resource Centre for Biological Material (DSMZ). The strain was propagated in the Alicyclobacillus spp. medium (AAM) and incubated at $45^{\circ} \mathrm{C}$ with a stirring rate of $120 \mathrm{rpm}$ for $18 \mathrm{~h}$. AAM broth contained yeast extract (2.0 $\mathrm{g})$, glucose $(2.0 \mathrm{~g}),\left(\mathrm{NH}_{4}\right)_{2} \mathrm{SO}_{4}(0.4 \mathrm{~g}), \mathrm{MgSO} \cdot 7 \mathrm{H}_{2} \mathrm{O}(1.0 \mathrm{~g}), \mathrm{CaCl}_{2}$ $(0.38 \mathrm{~g}), \mathrm{KH}_{2} \mathrm{PO}_{4}(1.2 \mathrm{~g})$, distilled water $(1 \mathrm{~L})(\mathrm{pH} 4.2)$.

The antimicrobial activity of nisin-IONPs composites was assayed via the agar well diffusion method with minor modifications. ${ }^{27}$ Briefly, the assay plates consisted of two layers. The bottom layer was covered with $10 \mathrm{~mL}$ of $2 \%$ sterile agar. After agar solidification, sterile Oxford cups (diameter $9 \mathrm{~mm}$ ) were placed lightly on the samples. Then, $10 \mathrm{~mL}$ AAM soft agar (1\% agar) mixed with approximately $10^{6} \mathrm{CFU} \mathrm{mL} \mathrm{m}^{-1}$ freshly grown indicator strain cells of A. acidoterrestris DSM 3923 was poured on the upper layer. Oxford 

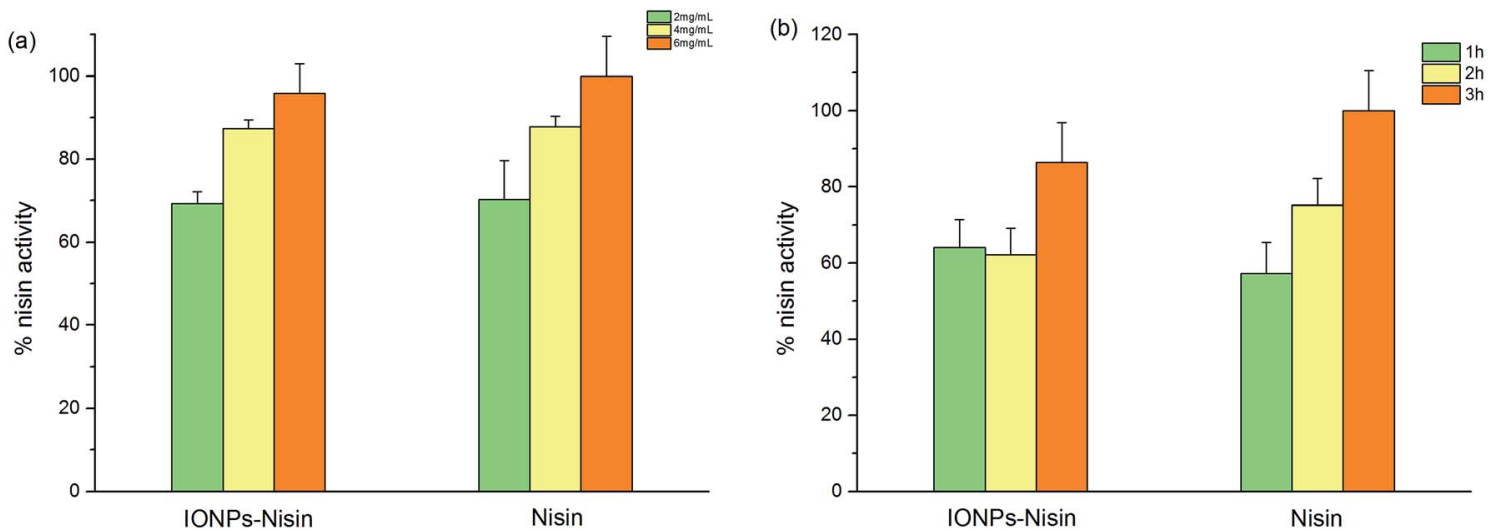

Fig. 9 CFDA-SE leakage assay with nisin and IONP-nisin composites against A. acidoterrestris DSM 3923.
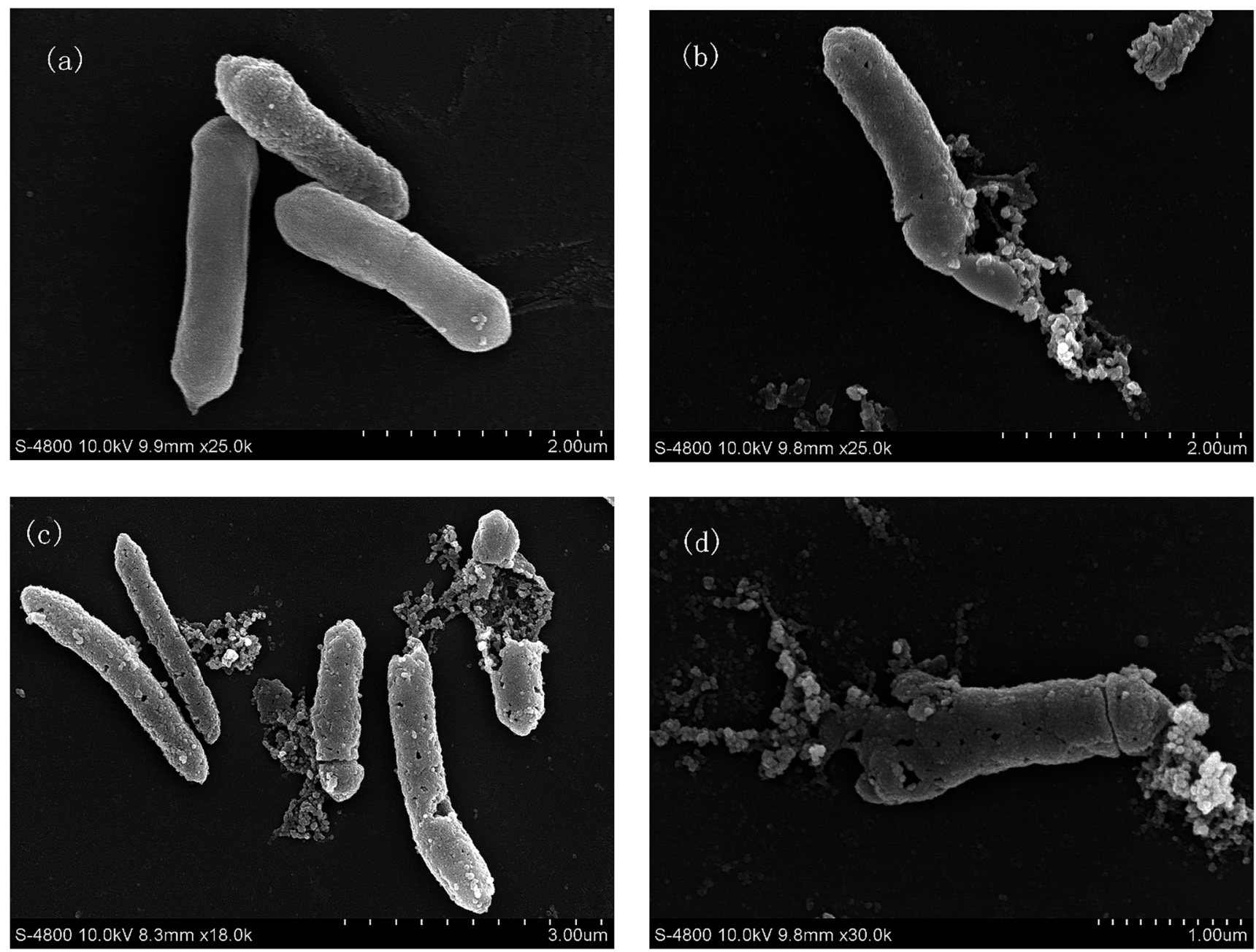

Fig. 10 Morphological changes of A. acidoterrestris DSM 3923 after treatment with IONPs-nisin composites (a) untreated control, (b) and (c) treated for $1 \mathrm{~h}$, (d) for $2 \mathrm{~h}$.

cups were removed after solidification, and $100 \mu \mathrm{L}$ of the specimen was added to each well. The plates were stored at $4{ }^{\circ} \mathrm{C}$ for $2 \mathrm{~h}$ to allow sufficient sample diffusion. The samples were then incubated at $45^{\circ} \mathrm{C}$ for $18 \mathrm{~h}$, and the zone of inhibition was measured to assay the antimicrobial activity.
Synthesis of iron oxide nanoparticles (IONPs)

The IONPs were prepared via an earlier known method. ${ }^{28}$ The most easily performed method uses co-precipitation based on the following mechanism: $\mathrm{Fe}^{2+}+2 \mathrm{Fe}^{3+}+8 \mathrm{OH}^{-} \leftrightarrows \mathrm{Fe}(\mathrm{OH})_{2}+$ $2 \mathrm{Fe}(\mathrm{OH})_{3} \rightarrow \mathrm{Fe}_{3} \mathrm{O}_{4} \downarrow+4 \mathrm{H}_{2} \mathrm{O} .^{25}$ Briefly, aqueous $\mathrm{FeSO}_{4}$ and 
$\mathrm{Fe}(\mathrm{NO})_{3}$ solution $(0.1 \mathrm{M}$ each) were mixed at $1: 1$. The mixture was then stirred for $30 \mathrm{~min}$ followed by the addition of $3.0 \mathrm{mM}$ SDS with stirring for another $30 \mathrm{~min}$. Then, triethylamine $(\sim 5 \%$ $\mathrm{v} / \mathrm{v}$ ) was added dropwise under vigorous stirring for $2 \mathrm{~h}$. Before adding the base, the $\mathrm{pH}$ of this system was kept at 2.0-3.0. The entire process was done under stirring to assure homogeneity. The color of the suspension turned from dark brown to complete black after $5 \mathrm{~h}$ of vigorous stirring. The magnetic precipitates were washed with several rounds of sonication using MilliQ water and methanol to remove unreacted chemicals and other impurities. The particles were vacuum freezedried overnight to yield IONPs.

\section{Optimization of IONPs-nisin composite preparation conditions}

A $1 \mathrm{mg} \mathrm{mL}^{-1}$ solution of nisin (10 $000 \mathrm{IU} \mathrm{mL}^{-1}$ ) was prepared in sterile phosphate buffer with $\mathrm{pH}$ values of $2-10$. Then, different amounts of IONPs $\left(0.5 \mathrm{mg} \mathrm{mL}^{-1}, 1 \mathrm{mg} \mathrm{mL}^{-1}, 2 \mathrm{mg} \mathrm{mL} \mathrm{m}^{-1}, 3 \mathrm{mg}\right.$ $\mathrm{mL}^{-1}$ and $4 \mathrm{mg} \mathrm{mL}^{-1}$ ) were added to the different $\mathrm{pH}$ values. After incubation at $4{ }^{\circ} \mathrm{C}(0.5 \mathrm{~h}, 1 \mathrm{~h}, 2 \mathrm{~h}, 3 \mathrm{~h}$ and $4 \mathrm{~h})$ under mild shaking, the solution was separated magnetically using a horseshoe magnet. The pelleted IONPs-nisin composites were washed twice with sterile phosphate buffer $(\mathrm{pH}$ 7.0) and resuspended in the same buffer. The antimicrobial activity was measured using the agar well diffusion method to determine the best nisin-IONPs composition.

To confirm the maximum adsorption of IONPs/nisin, a 10

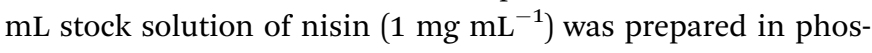
phate buffer ( $\mathrm{pH} 7.0,0.1 \mathrm{M}$ ). Then, $10 \mathrm{mg}$ IONPs were added to the nisin solution and incubated for $1 \mathrm{~h}$ under mild shaking to form IONPs-nisin composites followed by magnetic separation of the composites. This was repeated 10 times, and $100 \mu \mathrm{L}$ of the supernatant was reserved after each reaction. Both IONPs-nisin composites and the homologous supernatants were used in antimicrobial assays via the agar well diffusion method. The maximum adsorption proportion was calculated by observing the zone of inhibition.

\section{Materials characterization}

The IONPs were characterized with multiple techniques. Transmission electron microscopy (TEM, JEOL 2000F, Japan) with $200 \mathrm{kV}$ accelerating voltage was used to observe the morphology and particle size. The magnetic properties were measured using vibrating sample magnetometry (VSM-7307, Lake Shore, USA). A Zetasizer Nano ZS (90, Malvem, UK) was used to investigate the zeta potential of the IONPs. X-ray diffraction (XRD) measurements used X-ray diffractometer (XRD, BRUKER D8 ADVANCE, German). Fourier transform infrared spectrometer (FT-IR, Vetex70, BRUKER, German) was used to confirm the chemical composition of IONPs-nisin.

\section{Antimicrobial activity of IONPs-nisin composites}

Sensitivity to $\mathbf{p H}$ and temperature. To investigate the $\mathrm{pH}$ stability, IONPs-nisin composites were added into the following buffers (20 mM): glycine- $\mathrm{HCl}(\mathrm{pH} 2.0)$, citric acid phosphate (pH 3.0, 4.0, 5.0 and 6.0), PBS (pH 7.0), Tris- $\mathrm{HCl}$ (pH 8.0 and 9.0) and glycine- $\mathrm{NaOH}(\mathrm{pH} 10.0,11.0$ and 12.0). After $2 \mathrm{~h}$ of incubation at $4{ }^{\circ} \mathrm{C}$, the IONPs-nisin composites were separated by a magnet and resuspended in the PBS ( $\mathrm{pH}$ 7.0). The antimicrobial activity of the composites was again determined via the agar well diffusion method.

To investigate the heat stability, IONPs-nisin composites were resuspended in PBS ( $\mathrm{pH} 7.0$ ) and treated at $40{ }^{\circ} \mathrm{C}, 60{ }^{\circ} \mathrm{C}$, $80{ }^{\circ} \mathrm{C}$ and $100{ }^{\circ} \mathrm{C}$ in a water bath for $60 \mathrm{~min}$. After each treatment, the IONPs-nisin composites were immediately cooled in ice water, and the residual activity was tested with the agar well diffusion method mentioned before.

\section{Storage study}

The IONPs-nisin composites were stored at $4{ }^{\circ} \mathrm{C}$ for 7 days. During storage, the samples were withdrawn periodically (days $1,3,5$, and 7), and the residual activities were assayed by agar well diffusion method. The inhibitory zone diameters of the treated samples and the control samples were both measured. The control samples were defined as $100 \%$ and the other samples were compared to this baseline.

\section{Minimum inhibitory concentration (MIC)}

IONPs-nisin composites were serially diluted in sterile PBS ( $\mathrm{pH}$ 7.0). Thereafter, $10 \mu \mathrm{L}$ diluted solution was mixed with $90 \mu \mathrm{L}$ medium (AAM, pH 4.2) containing $10^{6} \mathrm{CFU} \mathrm{\textrm {mL } ^ { - 1 }}$ A. acidoterrestris DSM 3923. The mixture was added to 96-well microtiter plates and cultivated at $45{ }^{\circ} \mathrm{C}$ for $24 \mathrm{~h}$. The controls were 10 $\mu \mathrm{L}$ sterile PBS ( $\mathrm{pH}$ 7.0) mixed with bacterial culture under the same conditions. To exclude the interference of IONPs-nisin absorbance, the microtiter plate was placed in the field of a horseshoe magnet for $1 \mathrm{~min}$ to assemble the magnetic composites. Absorbance measurements of the mixture were carried out on a Microplate Reader (BIO-RAD, America) at $600 \mathrm{~nm}$ with three independent experimental samples. The MIC values were determined as the lowest concentration that resulted in an $\mathrm{OD}_{600}$ reading of $<0.1$.

\section{CFDA-SE leakage assay}

We used the carboxy fluorescein diacetate succinimidyl ester (CFDA-SE) leakage assay to demonstrate the cell membranedirected antibacterial activity of IONPs-nisin composites. ${ }^{24}$ The A. acidoterrestris DSM 3923 cells were incubated for $12 \mathrm{~h}$ and were collected by centrifugation at $8000 \mathrm{rpm}$ for $8 \mathrm{~min}$. After washing twice with sterile PBS, the cell pellet was resuspended in $10 \mathrm{~mL}$ labeling buffer with $20 \mu \mathrm{L}$ of CFDA-SE. This was incubated for $20 \mathrm{~min}$ at $37{ }^{\circ} \mathrm{C}$ in the dark. The cells were subsequently washed three times with PBS and centrifuged at $8000 \mathrm{rpm}$ for $8 \mathrm{~min}$.

After staining, $10^{6} \mathrm{CFU} \mathrm{\textrm {mL } ^ { - 1 }}$ labeled cells were treated with IONPs-nisin composites and nisin solutions of varying concentrations at $45{ }^{\circ} \mathrm{C}$ for 1,2 , or $3 \mathrm{~h}$. The cells were also treated with PBS buffer under the same conditions as control samples. Then, cell free supernatants of all samples were collected by centrifuging at $8000 \mathrm{rpm}$ for $15 \mathrm{~min}$. The fluorescence of the supernatant was measured with fluorescence spectrophotometry (F-7000, HITACHI, Japan) with a slit width of $5 \mathrm{~nm}$, an excitation wavelength of $488 \mathrm{~nm}$, and an emission 
wavelength of $518 \mathrm{~nm}$. The fluorescence of the control was subtracted from the samples. This was expressed as the maximum nisin activity $(100 \%)$.

\section{Scanning electron microscope (SEM)}

SEM was used to observe the morphological changes of $A$. acidoterrestris DSM 3923 strain $\left(10^{7} \mathrm{CFU} \mathrm{mL}^{-1}\right)$ after treatment by IONPs-nisin composites and incubation at $45^{\circ} \mathrm{C}$ for $1 \mathrm{~h}$ and $2 \mathrm{~h}$ respectively. After magnetic separation of IONPs-nisin composites, the target cells were collected by centrifugation and fixed with $2.5 \%(\mathrm{v} / \mathrm{v})$ glutaraldehyde at room temperature for $2 \mathrm{~h}$. The cells were then washed three times for $10 \mathrm{~min}$ each time with PBS ( $\mathrm{pH} 7.2,0.1 \mathrm{M}$ ). Dehydration used successively treatments with ethanol: $30 \%, 50 \%, 70 \%, 80 \%$ and $90 \%$ ethanol for $10 \mathrm{~min}$ each. This was followed by $100 \%$ ethanol twice for $10 \mathrm{~min}$ and isoamyl acetate to replace ethanol. After drying with $\mathrm{CO}_{2}$ for $3 \mathrm{~h}$ and coating with gold $(10 \mathrm{mM})$, the cells were observed with SEM (S-4800, Hitachi, Japan).

\section{Statistical analysis}

All experiments were repeated in triplicate. ANOVA and Duncan's multiple range test were used to analyze the data; $p<0.05$ was considered statistically significant.

\section{Conclusions}

In this work, a charge-based approach was successfully used to obtain IONPs-nisin composites. The IONPs are ferromagnetic in nature and can be rapidly separated by an external magnetic field. FT-IR analysis confirmed the existence of nisin on the surface of IONPs. The $\mathrm{pH}$, thermal and storage stability of IONPs-nisin composites were held consistent with nisin. Moreover, the composites combined the advantages of bactericide and magnetic separation. The primarily antimicrobial mechanism of the composites might be pore formation in the cell membrane. The future work will focus on the interaction analysis between IONPsnisin composites and food ingredients such as protein, lipid, oxidative product and carbohydrates. More systematic research should be done before the practical application for the food sector.

\section{Acknowledgements}

This work was financially supported by the National Natural Science Foundation of China $(31671866,31371814)$ and major projects of strategic emerging industries in Shaanxi province of China (2016KTCQ03-12).

\section{References}

1 G. Cerny, W. Hennlich and K. Poralla, Z. Lebensm.-Unters. Forsch., 1984, 179, 224-227.

2 M. E. Parish and R. M. Goodrich, J. Food Prot., 2005, 68, 2196-2200.

3 P. Falcone, D. Campaniello, C. Altieri, M. Sinigaglia, M. Corbo, M. Anese and M. Del Nobile, Ital. J. Food Sci., 2003, 15, 142-151.
4 K. Yamazaki, H. Teduka and H. Shinano, Biosci., Biotechnol., Biochem., 1996, 60, 543-545.

5 W. H. Groenewald, P. A. Gouws and R. C. Witthuhn, Food Microbiol., 2009, 26, 71-76.

6 K. Goto, A. Nishibori, Y. Wasada, K. Furuhata, M. Fukuyama and M. Hara, Lett. Appl. Microbiol., 2008, 46, 289-294.

7 W. H. Groenewald, P. A. Gouws and R. C. Witthuhn, Extremophiles, 2008, 12, 159-163.

8 L. Albuquerque, F. Rainey, A. Chung, A. Sunna, M. Nobre, R. Grote, G. Antranikian and M. Da Costa, Int. J. Syst. Evol. Microbiol., 2000, 50, 451-457.

9 Y. Tianli, Z. Jiangbo and Y. Yahong, Compr. Rev. Food Sci. Food Saf., 2014, 13, 771-797.

10 Y. Smit, M. Cameron, P. Venter and R. C. Witthuhn, Food Microbiol., 2011, 28, 331-349.

11 C. E. Steyn, M. Cameron and R. C. Witthuhn, Int. J. Food Microbiol., 2011, 147, 1-11.

12 A. Bevilacqua, M. Sinigaglia and M. Corbo, Int. J. Food Microbiol., 2008, 125, 103-110.

13 A. A. de Oliveira Junior, H. G. S. de Araújo Couto, A. A. T. Barbosa, M. A. G. Carnelossi and T. R. de Moura, Int. J. Food Microbiol., 2015, 211, 38-43.

14 A. De Carvalho, E. Costa, H. Mantovani and M. Vanetti, J. Appl. Microbiol., 2007, 102, 1000-1009.

15 J.-P. Huertas, M.-D. Esteban, V. Antolinos and A. Palop, Food Control, 2014, 35, 73-78.

16 T. Pirttijärvi, G. Wahlström, F. Rainey, P. Saris and M. Salkinoja-Salonen, J. Ind. Microbiol. Biotechnol., 2001, 26, 107-114.

17 K. Yamazaki, M. Murakami, Y. Kawai, N. Inoue and T. Matsuda, Food Microbiol., 2000, 17, 315-320.

18 A. A. T. Barbosa, H. G. S. de Araújo, P. N. Matos, M. A. G. Carnelossi and A. A. de Castro, Int. J. Food Microbiol., 2013, 164, 135-140.

19 S. P. Ruiz, M. M. d. Anjos, V. S. Carrara, J. N. deLima, D. A. G. Cortez, T. U. Nakamura, C. V. Nakamura and B. A. Abreu Filho, J. Food Sci., 2013, 78, M1772-M1777.

20 M. Walker and C. A. Phillips, Food Control, 2008, 19, 974981.

21 B. Sokołowska, S. Skạpska, M. Fonberg-Broczek, J. Niezgoda, M. Chotkiewicz, A. Dekowska and S. Rzoska, High Pressure Res., 2012, 32, 119-127.

22 G. L. Blay, C. Lacroix, A. Zihler and I. Fliss, Lett. Appl. Microbiol., 2007, 45, 252-257.

23 B. P. Nellore, S. SekharáSinha, S. ReddyáChavva and P. ChandraáRay, RSC Adv., 2015, 5, 18881-18887.

24 M. D. Adhikari, G. Das and A. Ramesh, Chem. Commun., 2012, 48, 8928-8930.

25 W. Wu, Z. Wu, T. Yu, C. Jiang and W.-S. Kim, Sci. Technol. Adv. Mater., 2015, 16, 23501-23543.

26 J.-K. Xu, F.-F. Zhang, J.-J. Sun, J. Sheng, F. Wang and M. Sun, Molecules, 2014, 19, 21506-21528.

27 U. Schillinger and F. K. Lücke, Appl. Environ. Microbiol., 1989, 55, 1901-1906.

28 B. Saha, S. Das, J. Saikia and G. Das, J. Phys. Chem. C, 2011, 115, 8024-8033. 